\title{
Design and development of Building energy simulation Software for prefabricated cabin type of industrial building (PCES)
}

\author{
Jun ZHANG $^{1,2}$, Ri Yi LI ${ }^{1}$ \\ ${ }^{1}$ South China University of Technology, State Key Laboratory of Subtropical Building Science, Guangdong Guangzhou 510640, \\ China; \\ ${ }^{2}$ China Energy Engineering Group Guangdong Electric Power Design Institute Co., Ltd., Guangzhou 510663, China
}

\begin{abstract}
Building energy simulation is an important supporting tool for green building design and building energy consumption assessment, At present, Building energy simulation software can't meet the needs of energy consumption analysis and cabinet level micro environment control design of prefabricated building. thermal physical model of prefabricated building is proposed in this paper, based on the physical model, the energy consumption calculation software of prefabricated cabin building(PCES) is developed. we can achieve building parameter setting, energy consumption simulation and building thermal process and energy consumption analysis by PCES.
\end{abstract}

\section{Introduction}

The background of PCES design and development of prefabricated compartment industrial building energy consumption simulation software mainly includes the following three aspects:

1) Prefabricated cabin buildings are faced with unprecedented opportunities for development: with the development of smart grid, as a center of power dispatching and control, intelligent substation will usher in a new wave of construction. Rapid growth in the number and size of substation integrated automation system. From this, prefabricated, assembled, compact and many other advantages of prefabricated cabin architecture came into being.

In practical application, prefabricated building module not only exist in the power industry, such as container data center, communications industry, mobile base station are prefabricated building module category, the common features for precast monolithic construction, lightweight enclosure structure, heat rejection to heat equipment fever; the difference of power equipment the tank body is not equipped with a, so the energy density is different.

2) The high energy consumption of industrial buildings has become a bottleneck restricting the development of prefabricated industrial buildings. Taking the power grid industry as an example, Only Guangzhou, Shenzhen and Dongguan three places, the number of $110 \mathrm{kV}$ and above substations as many as 771, although the power consumption of industrial building process huge base, substation building power consumption (including energy consumption of Technology) still accounted for the total power consumption of $26 \%{ }^{[1]}$. In the prefabricated class of buildings widely used in the communications industry, the situation is not optimistic, the entire telecommunications industry's annual electricity consumption has more than 20 billion $\mathrm{kwh}^{[2]}$, of which the base station power consumption accounted for $73 \%{ }^{[3]}$ of total electricity consumption.

High energy consumption, and the present situation of the project construction of prefabricated cabin supporting structure and most engineering application without such design, there is a lack of optimization in energy consumption.

3) The current building energy simulation software is not specially designed for prefabricated cabin industrial buildings, and has limitations. It is difficult to meet the needs of energy consumption analysis and cabinet level micro environment control design of prefabricated cabin buildings.

In the middle of $60 \mathrm{~s}$ of last century, Some scholars used dynamic simulation method to analyze the heat transfer characteristics of building envelope. with the rapid development of computer technology, a great deal of complex computing could be put into practice. Therefore, this short presentation of a number of building energy simulation software, including the United States' BLAST $^{[5]}$, DOE-2 ${ }^{[6]}$, Europe's ESP-r ${ }^{[4]}$, China's DeST ${ }^{[7]}$ and Japan's HASP, etc.. But the above research is to comfort people for the moderate target of environment control of civil construction type, and more to the building function zoning thermal environment as the research subject, the core operation simulation of cabinet level micro environment almost no parts of equipment.

\footnotetext{
*Corresponding author: Email: zhangjun@gedi.com.cn
} 


\section{Establishment of simplified calculation model of prefabricated building energy consumption}

\subsection{The foundation of building thermal physics model}

The thermal process disturbance of prefabricated cabin building has the following characteristics:

1) Periodic double outer disturbances: solar radiation and outdoor air temperature changes periodically;

2) Stability single interference: Prefabricated cabin type industrial buildings are unattended operation mode, no human body heat dissipation, in addition, cabin electrical equipment function for signal acquisition and relay protection of power system, industrial control. Under the condition of signal acquisition, data points and control and protection action, the internal heat disturbance of equipment is negligible and stable.

3) No room interference: Prefabricated cabin independent layout, no adjacent room;

\subsection{Establishment of building thermal physics model}

The sketch of the thermal physics model of the prefabricated building is shown in figure 1 .

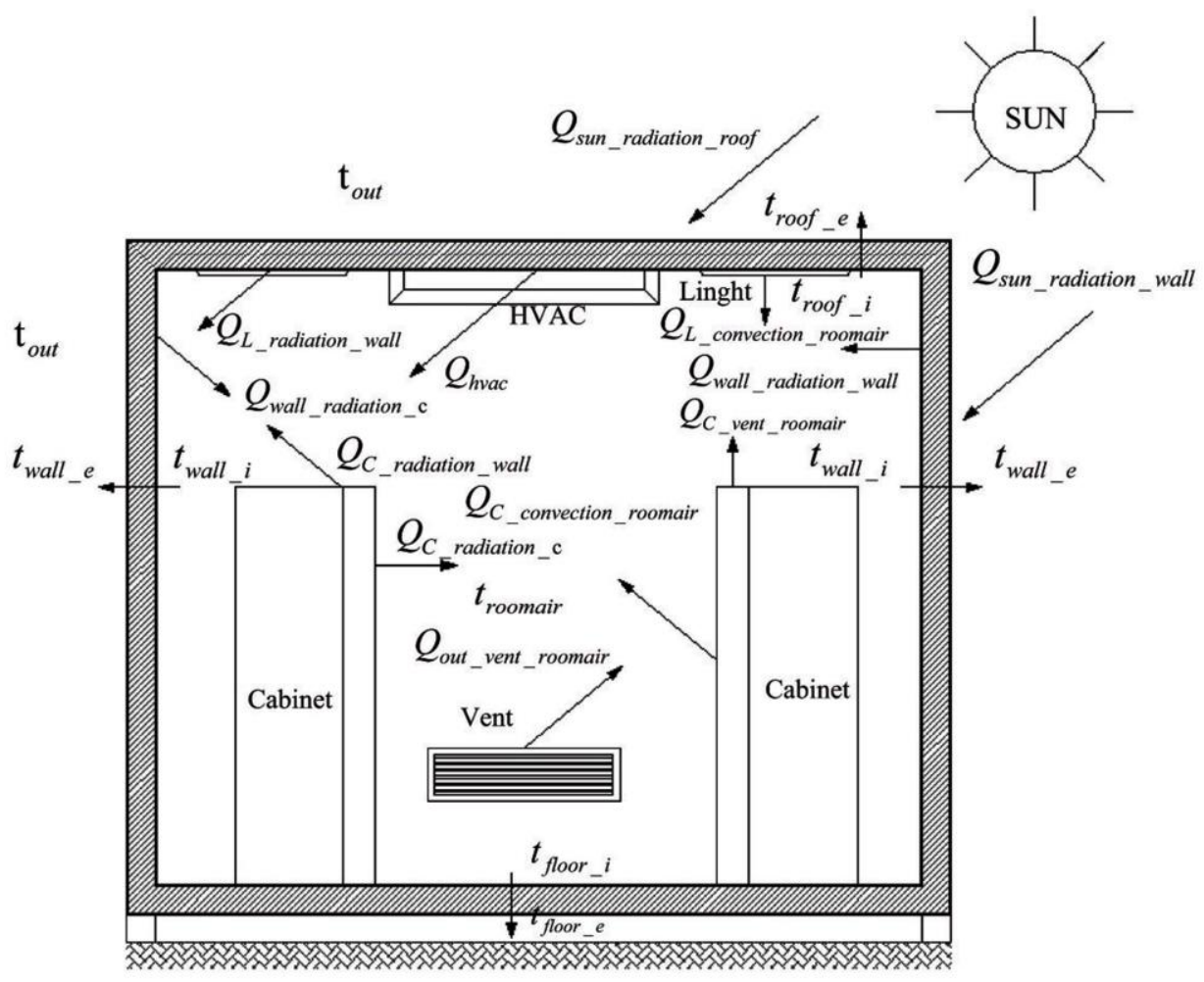

Figure 1 A physical model of building thermal processes

The meaning of each symbol in Figure 1 is shown in table 1.

Table 1 Various parameters of building thermal process

\begin{tabular}{|c|c|c|c|}
\hline $\begin{array}{c}t_{\text {out }} \\
t_{\text {wall-e }}\end{array}$ & $\begin{array}{c}\text { Outdoor dry bulb temperature } \\
\text { Exterior surface temperature of enclosure } \\
\text { structure }\end{array}$ & $\begin{array}{l}t_{\text {roomair }} \\
t_{\text {wall-air }}\end{array}$ & $\begin{array}{c}\text { Indoor air temperature } \\
\text { Internal surface temperature of } \\
\text { enclosure structure }\end{array}$ \\
\hline$t_{\text {roof }-e}$ & Roof surface temperature & $t_{\text {roof }-i}$ & Roof inner surface temperature \\
\hline$t_{\text {floor }-e}$ & Surface temperature of ground surface & $t_{\text {floor }-i}$ & Surface temperature of ground \\
\hline$Q_{l \text {-radiation-roomair }}$ & Thermal radiation disturbance of lamps & $Q_{l \text {-convection-roomair }}$ & Heat transfer disturbance of lamps \\
\hline$Q_{\text {sun-radiation-wall }}$ & Solar radiation heat disturbance in wall & $Q_{\text {sun-radiation-roof }}$ & $\begin{array}{c}\text { Solar radiation heat disturbance of } \\
\text { roof }\end{array}$ \\
\hline$Q_{c-\text { convection-roomair }}$ & $\begin{array}{l}\text { Heat disturbance of Cabinet convection heat } \\
\text { transfer }\end{array}$ & $Q_{c-v e n t-r o o m a i r}$ & $\begin{array}{l}\text { Heat disturbance of Cabinet } \\
\text { ventilation heat transfer }\end{array}$ \\
\hline$Q_{c-\text { radiation-c }}$ & $\begin{array}{l}\text { Long wave radiative heat transfer } \\
\text { of cabinet wall to other cabinet } \\
\text { walls }\end{array}$ & $Q_{c-\text { radiation-wall }}$ & $\begin{array}{l}\text { Long wave radiative heat disturbance } \\
\text { of enclosure wall by cabinet }\end{array}$ \\
\hline$Q_{\text {wall-radiation-wall }}$ & $\begin{array}{l}\text { Long wave radiative heat transfer } \\
\text { of enclosure wall facing other walls }\end{array}$ & $Q_{\text {wall-radiation-c }}$ & $\begin{array}{l}\text { Long wave radiation heat shock of } \\
\text { enclosure wall facing the wall of } \\
\text { cabinet }\end{array}$ \\
\hline$Q_{\text {hvac }}$ & $\begin{array}{l}\text { Room air conditioning cooling } \\
\text { capacity }\end{array}$ & $Q_{\text {out-vent-roomair }}$ & Outdoor ventilation heat disturbance \\
\hline
\end{tabular}

The building envelope heat balance system including outer surface heat balance of surface thermal model, heat transfer model, inner balance model; air heat balance system including heat balance model, heat balance model, 


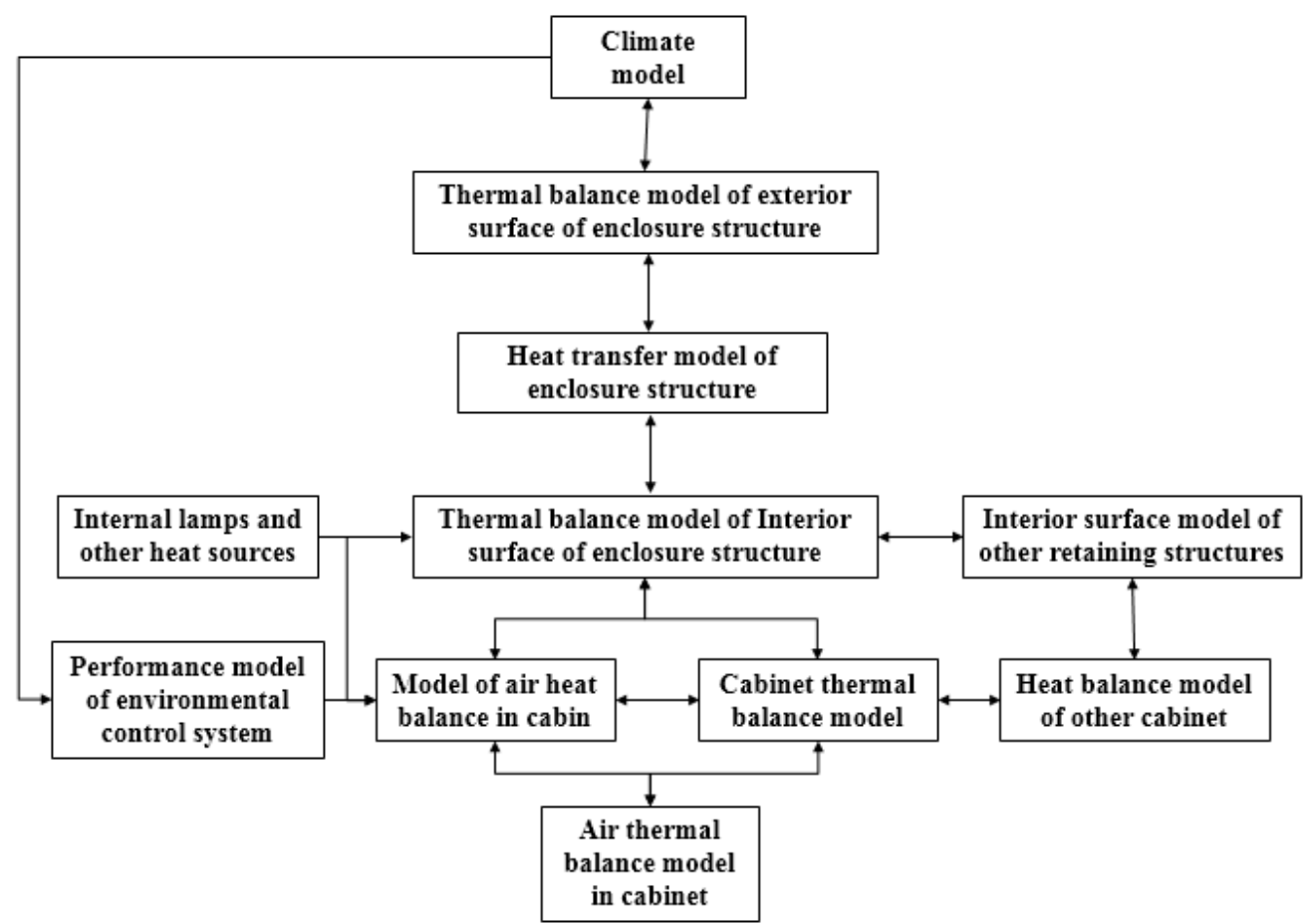

Figure2 Thermal equilibrium model system of prefabricated building

A heat balance equation can be established for the exterior surface of the enclosure:

$$
\begin{aligned}
q_{e}=\rho I+h_{c, e}\left(t_{0}-t_{e}\right) & +h_{r-e, 0}\left(t_{0}-t_{e}\right)+h_{r-e, s k y}\left(t_{s k y}-t_{e}\right) \\
& +h_{r-e, g}\left(t_{g}-t_{e}\right)
\end{aligned}
$$

$q_{e}$ is the exterior wall heat flux, $\mathrm{W} / m^{2} ; \rho$ is the outer surface of the absorption rate of shortwave radiation; $I$ is the total solar radiation intensity, the outer surface of $\mathrm{W} / \mathrm{m}^{2} ; h_{c, e}$ is the exterior surface of the convective heat transfer coefficient, $\mathrm{W} /\left(\mathrm{m}^{2} \cdot K\right) ; t_{0}$ is the outdoor dry bulb temperature, $\mathrm{K} ; t_{e}$ is the external surface temperature of $\mathrm{K} ; t_{s k y}$ is $\mathrm{K} ; t_{g}$ is the sky temperature, surface temperature, $\mathrm{K} ; h_{r-e, 0}$ is the exterior surface long wave radiation between the outdoor air and the heat transfer coefficient, $\mathrm{W} /\left(\mathrm{m}^{2} \cdot K\right)$; $h_{r-e, s k y}$ is the exterior surface and space day long wave radiation heat transfer coefficient, $\mathrm{W} /\left(\mathrm{m}^{2} \cdot K\right)$;

$$
q_{i}=h_{c, i}\left(t_{r}-t_{i}\right)+\sum_{k=1}^{N_{i}} h_{r-i k}\left(t_{i-k}-t_{i}\right)+\sum_{k=1}^{N_{c}} h_{r-i k}\left(t_{c e-k}-t_{i}\right)+\frac{Q_{L}\left(1-C_{1}\right)}{F_{\text {tol }}}
$$

$q_{i}$ is through the building envelope, the heat flux into the room by room outside, $W / m^{2} ; h_{c, i}$ is the inner surface of the convective heat transfer coefficientW $/\left(m^{2} \cdot K\right) ; t_{i}$ is the surface temperature of the enclosure structure, $t_{r}$ is the indoor air temperature, $\mathrm{K} ; t_{i-k}$ is the first $\mathrm{k}$ wall temperature, $\mathrm{K} ; t_{c-k}$ is the $\mathrm{k}$ $h_{r-e, g}$ is longwave radiation and surface between the wall surface heat transfer coefficient, $\mathrm{W} /\left(\mathrm{m}^{2} \cdot K\right)$.

The heat balance equation of the enclosure structure is:

$$
\begin{gathered}
q_{\lambda}=\frac{t_{e}-t_{i}}{\sum R} \\
\sum R=\frac{d}{\lambda}
\end{gathered}
$$

$q_{\lambda}$ is a heat retaining structure of heat flux density, $\mathrm{W} / \mathrm{m}^{2} ; \sum R$ is thermal resistance of building envelope, $m^{2} \cdot K / W ; t_{i}$ is the surface temperature of the outer walls, $\mathrm{K}$.

The heat balance equation can be established for the inner surface of the enclosure :

$$
\begin{aligned}
c_{p} \rho_{e} V_{r a} \frac{d t_{r a}}{d_{\tau}}= & \sum_{k=1}^{N_{i}} h_{c, i} F_{i-k}\left(t_{i-k}-t_{r a}\right)+c_{p} \rho_{e} V_{e}\left(t_{o}-t_{r a}\right)+Q_{L} C_{1} \\
& +\sum_{k=1}^{N_{c}} F_{c e-k} h_{c, c}\left(t_{c e-k}-t_{r a}\right)+\sum_{k=1}^{N_{c}} c_{p} \rho_{e} V_{c a-k}\left(t_{c a}-t_{r a}\right)+Q_{a c}
\end{aligned}
$$


$c_{p} \rho_{e} V_{r a} \frac{d t_{r a}}{d_{\tau}}$ is incremental sensible heat room air per unit time , W; $F_{i-k}$ is the $\mathrm{k}$ wall surface area, $m^{2} ; t_{r a}$ is the air temperature of the cabin, $K ; c_{p}$ is the specific heat capacity at constant pressure air, $J /(k g \cdot K) ; \rho_{e}$ is the air density, $\mathrm{kg} / \mathrm{m}^{3} ; V_{e}$ is indoor ventilation, $\mathrm{m}^{3}$; $h_{c, c}$ is a cabinet wall facing the flow heat transfer coefficient; $t_{c e-k}$ is the $\mathrm{k}$ cabinet surface temperature,

$$
\begin{gathered}
\frac{d Q_{C}}{d \tau}=Q_{C}+c_{p} \rho_{e} V_{c a}\left(t_{r a}-t_{c a}\right)+F_{c e} h_{c, c}\left(t_{r a}-t_{c e}\right)+\sum_{k=1}^{N_{i}} h_{r-c i} F_{c e}\left(t_{i-k}-t_{c e}\right) \\
+\sum_{k=1}^{N_{c e}} F_{c e} h_{r-c c}\left(t_{c e-k}-t_{c e}\right)
\end{gathered}
$$

$K ; F_{c e-k}$ is the k cabinet the outer wall of the surface area, $m^{2} ; V_{c a-k}$ is the $\mathrm{k}$ cabinet ventilation air exchange, $\mathrm{m}^{3} ; Q_{a c}$ is the air conditioning system in heat sensible heat, $\mathrm{W}$.

The heat balance equation can be established by taking a single cabinet as an isolator:
For the air in the cabinet, a heat balance equation can be established:

$$
\begin{gathered}
c_{p} \rho_{e} V_{r a} \frac{d t_{c a}}{d \tau}=F_{c e} h_{c, c}\left(t_{c, i}-t_{c a}\right)+F_{c e} h_{c, c}\left(t_{c, e}-t_{c a}\right)+c_{p} \rho_{e} V_{c a}\left(t_{r a}\right. \\
\left.-t_{c a}\right)
\end{gathered}
$$

The building heat balance equations are composed of the envelope structure, the indoor air, the cabinet and the heat balance equations of the air in the cabinet, so as to establish the building heat balance equations.

\section{Prefabricated compartment industrial building energy consumption simulation software development}

\subsection{Requirements analysis and interface design}

The target users of the prefabricated building energy consumption calculation software PCES include the prefab, the designer and the operation manager, and the software should operate under the Windows operating system, taking into account the user's needs. The main functions of the software include parameter setting, energy consumption simulation, building thermal process and energy consumption analysis.

Building energy simulation: under the given climatic parameters and environmental control objectives, the energy consumption of each part of the building is solved. building thermal process analysis: the temperature of bulkhead surface, air temperature in cabin and temperature distribution in cabin are solved under the given boundary conditions such as climate parameter and environment control target or energy consumption target.

\subsection{Software process}

The software calculation process is shown below: 


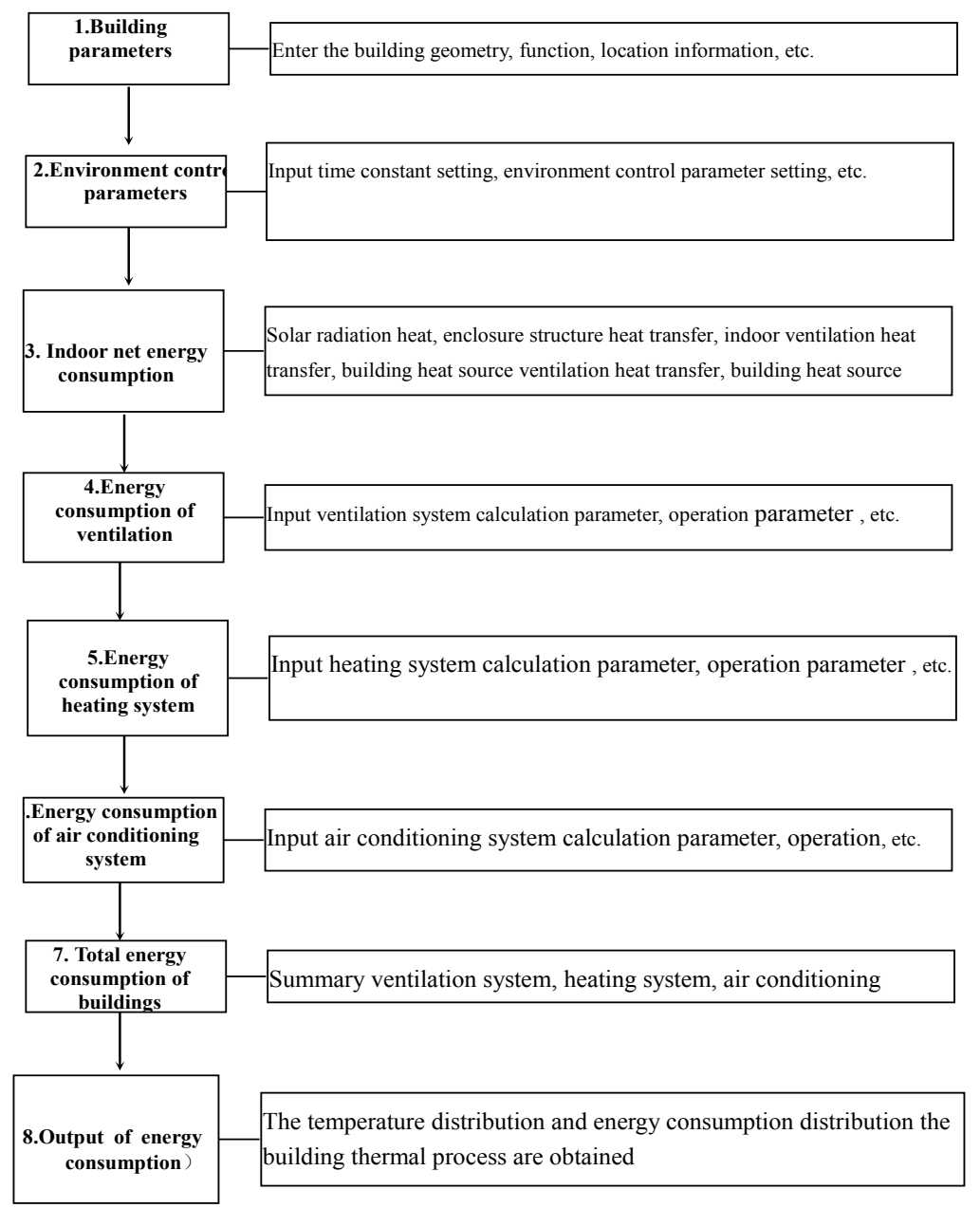

Figure 3 Processing flow of PCES

\section{Conclusion}

Based on the heat transfer of building construction prefabricated cabin ideal building thermal physical model theory, and based on the physical model of the development of prefabricated cabin building energy consumption calculation software PCES, analysis of setting, energy consumption simulation and building thermal process and energy consumption to achieve the construction parameters, accuracy finally through the calculation results of the model test method is verified.

Prefabricated cabin class building energy consumption calculation software PCES can be achieved by solving the prefabricated cabin building envelope, cabin heat and cabinet level thermal environmental conditions, and the results are accurate, suitable for engineering design and energy saving analysis.

\section{References}

1. Li Tienan, National Center for industrial energy saving and emission reduction technology promotion center. Progress report on China's industrial energy saving. 2013: medium term progress in 12th Five-Year, [M]., China Quality Inspection press,
China Standard Press, 2014.

2. Qin ting. Energy consumption analysis of communication base station [J]. Journal of Xi'an University of Posts and telecommunications, 2011, 16 (2): 76-78.

3. Liao Xiaofang, Xiang Bing, Xie Fengzhu, et al. Energy consumption analysis and integrated energy saving solution for mobile communication base station $[\mathrm{J}]$. telecommunications engineering technology and standardization, 2010, 23 (4): 53-57.

4. Hittle D C. The Building Loads Analysis and System Thermodynamics (BLAST) program, version 2.0. Users manual, volume 1[J]. 1979.

5. Yan D, Xia J, Tang W, et al. DeST - An integrated building simulation toolkit Part I: Fundamentals[J]. Building Simulation, 2008, 1(2):95-110.

6. Michael J, Witte, RH Henninger, J Glazer . TESTING AND VALIDATION OF A NEW BUILDING ENERGY SIMULATION PROGRAM [J]. Seventh International IBPSA Conference,2001: 353-359.

7. Yan D, Xia J, Tang W, et al. DeST - An integrated building simulation toolkit Part I: Fundamentals[J]. Building Simulation, 2008, 1(2):95-110. 